\title{
Off-Axis Current Drive with Helicon Waves for CFETR
}

\author{
Yuqing Yang ${ }^{1}\left(\mathbb{D} \cdot\right.$ Xinjun Zhang $^{2} \cdot$ Yanping Zhao $^{2} \cdot{\text { Chengming } \text { Qin }^{2}}^{2}$
}

Accepted: 7 December 2020 / Published online: 3 January 2021

(C) The Author(s) 2021

\begin{abstract}
Off-axis current drive is necessary for Tokamak to maintain and regulate the current profile. Helicon wave is the high order harmonic fast wave and helicon wave current drive (HCD) is one of the key issues in the China Fusion Engineering Test Reactor (CFETR). The theory of HCD is briefly introduced and the simulation results are listed. Helicon waves can realize off-axis current drive under CFETR plasma parameters when the frequency is greater than $1 \mathrm{GHz}$ and drive current is insensitive to the launched value of the parallel index of refraction $n_{\|}$, so wave accessibility issues can be reduced. Travelling Wave Antenna was analyzed by the commercial software package-CST. Near the resonant frequency of the antenna, the Voltage Standing Wave Ratio $<1.2$ is obtained for the antenna in the bandwidth of $50 \mathrm{MHz}$, which means that the antenna does not require a matching system.
\end{abstract}

Keywords CFETR · Current drive · Helicon wave

\section{Introduction}

China Fusion Engineering Test Reactor (CFETR) [1, 2] provided with high performance and large geometry is the next generation fusion device in China, which will be operated in two phases: Steady-state operation and selfsufficiency will be the two key issues for Phase I with a modest fusion power of up to $200 \mathrm{MW}$; Phase II aims for DEMO validation with a fusion power over $1 \mathrm{GW}$ [3]. The preliminary physical design under different operating modes, the engineering conceptual design of key components such as the vacuum chamber and its internal components have been completed [4]. CFETR includes superconducting magnet system, vacuum chamber, cladding, strainer, internal and external cold screen, and other components. The multi-dimensional physical design of CFETR gives several different schemes of standard operating modes [5-7].

Non-inductive current drive is needed to complement the bootstrap current to realize the steady-state operation

Yuqing Yang

yyq6069@mail.ustc.edu.cn

1 Wuxi Institute of Technology, Wuxi 214121, China

2 Chinese Academy of Sciences Institute of Plasma Physics, Hefei 230031, China
[8]. Non-inductive current drive include lower hybrid current drive (LHCD), electronic cyclotron current drive (ECCD), fast wave current drive (FWCD) and neutral beam current drive (NBCD) [9-11]. The experimental results show that LHCD can achieve high drive efficiency, but with two disadvantages: (1) Electron power decays greatly beyond a density limit [12]; (2) at the high electron temperatures characteristic of reactors, modelling shows that the LH wave is damped on thermal electrons near the plasma boundary, so the wave may not penetrate to the plasma core. Helicon wave is the high-order harmonics (20-40) of ion cyclotron (IC) and frequency range is $\omega_{\text {ci- }}$ $\ll \omega<\omega_{\mathrm{LH}}$, where $\omega_{\mathrm{ci}}, \omega, \omega_{\mathrm{LH}}$ are ion cyclotron frequency, wave frequency and lower hybrid frequency separately. HCD belongs to FWCD and is a variation on 'conventional' LHCD, and has been suggested for driving the plasma current in DEMO [1, 13]. The total driven current by helicon wave is not very sensitive to the launched $n_{\|}$. The travelling wave antenna is a good option for launching the wave with a very narrow $n_{\|}$spectrum. [14]. The layout of this article is as follows: "Helicon Current Drive" will be described in section 2. Main calculation results of HCD for CFETR will be discussed in "GENRAY Calculations for CFETR" section. The content of antenna optimization is also given in this paper "Travelling Wave Antenna" section. Finally, the "Conclusions" will be given in section 5 . 


\section{Helicon Current Drive}

From cold plasma dispersion relation [15], the FW group velocity is given [16]

$v_{\mathrm{g} \perp}=\frac{\partial \omega}{\partial k_{\perp}} \approx \frac{c}{n_{\perp}} \frac{\omega_{p i}^{2}}{\omega^{2}\left(1+\gamma-n_{\|}^{2}\right)}\left(\gamma=\omega_{\mathrm{pe}}^{2} / \omega_{\mathrm{ce}}^{2}\right)$

$v_{\mathrm{g} \|}=\frac{\partial \omega}{\partial k_{\|}}=c \frac{n_{\|}}{\left(1+\gamma-n_{\|}^{2}\right)}$

where $v_{\mathrm{g} \perp}$ and $v_{\mathrm{g} \|}$ are the perpendicular and parallel group velocity, respectively. $k_{\perp}$ and $k_{\|}$are the perpendicular and parallel wave number, respectively. If the damping is strong enough, then the wave damping will produce offaxis, heating and current drive. Current drive was found to be insensitive to the launched value of the parallel index of refraction $n_{\|}$, so wave accessibility issues can be reduced [17].

\section{GENRAY calculations for CFETR}

Calculations results of HCD in CFETR plasmas using GENRAY ray tracing code [18] will be shown in this section. GENRAY uses several different dispersion function models, where the magnetized cold plasma with electrons and an arbitrary number of ions has been used in this paper. The beam is emitted at an initial angle. The parallel refractive index $n_{\|}$is initially concentrated at 3 . The influence of the wave frequency, the antenna parallel refractive index, the poloidal emission position of the ray and the plasma parameters (electron temperature and electron density) on the current drive are analyzed. Here we use the model from Chiu [19] for wave absorption on electrons and for current drive the standard Ehst-Karney model [20] is used.

\section{Wave Frequency}

The CFETR simulation work in this paper is based on the design scheme of large size CFETR. The electron density, electron temperature and $Z_{\text {eff }}$ is shown in Fig. 1 as a function of the square root of the normalized toroidal flux, $\rho$ [21]. The main operating parameters are listed as: major radius $R=6.6 \mathrm{~m}$, minor radius $a=1.8 \mathrm{~m}$, toroidal magnetic field $B_{\mathrm{T}}=6 \mathrm{~T}$, plasma current $I_{\mathrm{p}}=7.6 \mathrm{MA}$, plasma center electron density $n_{\mathrm{e}}=7.84 \times 10^{19} \mathrm{~m}^{-3}$, deuterium ion density in plasma center $n_{\mathrm{D}}=3.27 \times 10^{19} \mathrm{~m}^{-3}$, tritium ion density in plasma center $n_{\mathrm{T}}=3.27 \times 10^{19} \mathrm{~m}^{-3}$, helium ion density in plasma center $n_{\mathrm{He}}=0.39 \times 10^{19}$ $\mathrm{m}^{-3}$, inert gas $n_{\mathrm{Ar}}=0.0023 \times 10^{19} \mathrm{~m}^{-3}$, center electron
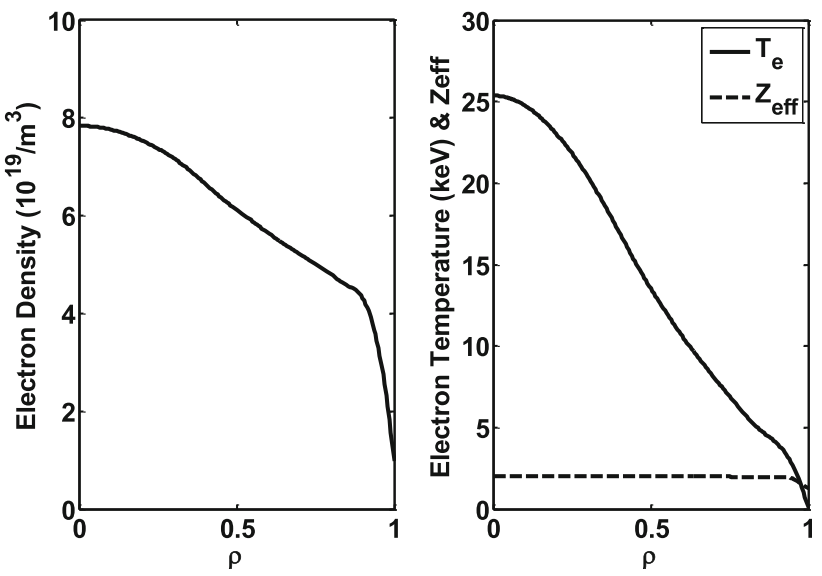

Fig. 1 Electron density, electron temperature and $Z_{\text {eff }}$ profile versus the normalized small radius $\rho$

temperature in plasma center $T_{\mathrm{e}}=25.37 \mathrm{keV}$, center ion temperature in plasma center $T_{\mathrm{i}}=18.98 \mathrm{keV}$.

Poloidal cross section, profiles of driven current density and absorption power profiles of electron and ion under different frequencies are shown in Fig. 2. The shape of absorption profile is the same as of the current drive. The peak current position for high frequency exists more inside than low frequency and the current drive profile is wider at higher frequencies. The possible reason is that the electron damping is stronger for higher harmonics. When the fast wave frequency increases, the ion interaction becomes weaker. Frequency variation really is an effective tool to control the radial helicon beam propagation, especially as a tool for the RF driven current radial profile control, which also be verified in ITER [16].

\section{Parallel refractive index}

Launching fast waves results in lower $n_{\|}$, there are two main reasons: (1) the larger the value of $n_{\|}$, the stronger the attenuation of the field in the vacuum area near the antenna; (2) the smaller $n_{\|}$is beneficial to reduce the local electric field, which may lead to electrical failure of the antenna. Considering the accessibility of waves [22], $n_{\|}$has a critical value. Fast waves below this value will be converted to slow waves at the plasma boundary. The critical value is $n_{\| c r i t}$ and $n_{\|}$spectrum should avoid approaching or below $n_{\| c r i t}$ to avoid fast wave converting to slow wave.

$\mathrm{n}_{\|}>\mathrm{n}_{\| \text {crit }} \equiv\left[1-\left(\frac{\omega^{2}}{\omega_{\mathrm{ce}} \omega_{\mathrm{ci}}}\right)\right]^{-1 / 2}$

This value is about 2.1 for D III-D device parameters, 1.23 for FNSF device parameters and 1.2 for CFETR device parameters (magnetic field intensity is 5T). As shown in Fig. 3, the total driven current is not very sensitive to the launched $n_{\|}$within some range, where $n_{\|}$was 
Fig. 2 Poloidal cross section, profiles of driven current density, and absorption power profiles of electron and ion for $B_{\mathrm{T}}=6 \mathrm{~T}, I_{\mathrm{p}}=7.6 \mathrm{MA}$, $n_{\mathrm{e}}=7.84 \times 10^{19} \mathrm{~m}^{-3}$, $T_{\mathrm{e}}=25.37 \mathrm{keV}, n_{\|}=3$. Rays emit from the middle plane of the low field side. The central ray is shown for $1.1 \mathrm{GHz}$ and $2.0 \mathrm{GHz}$ in $\mathbf{a}$ and $\mathbf{b}$ separately, $\mathbf{c}$ and $\mathbf{d}$ give the profiles of driven current density for case of $\mathbf{a}$ and $\mathbf{b}$ separately, (e) and (f) give the absorption power profiles for case of (a) and (b) separately
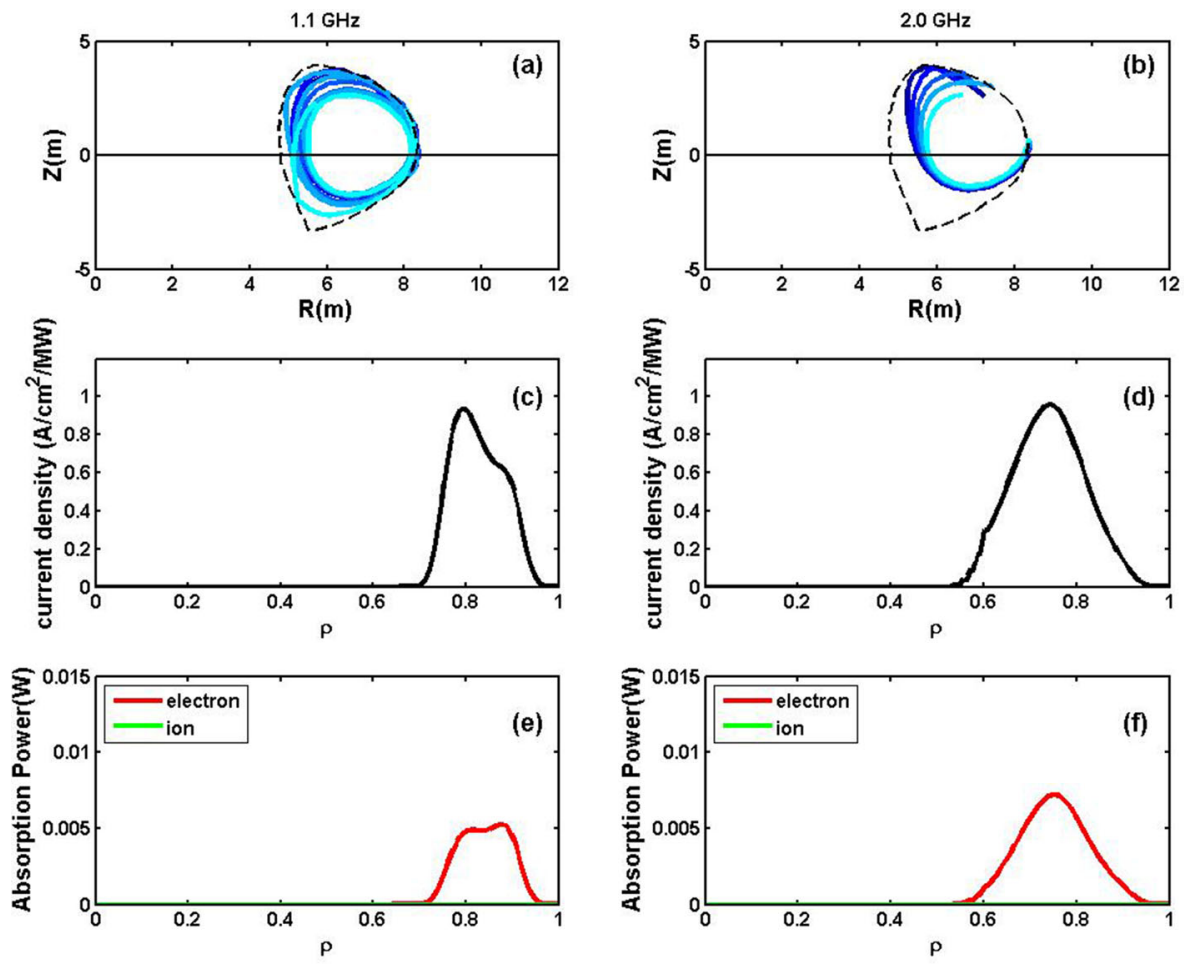

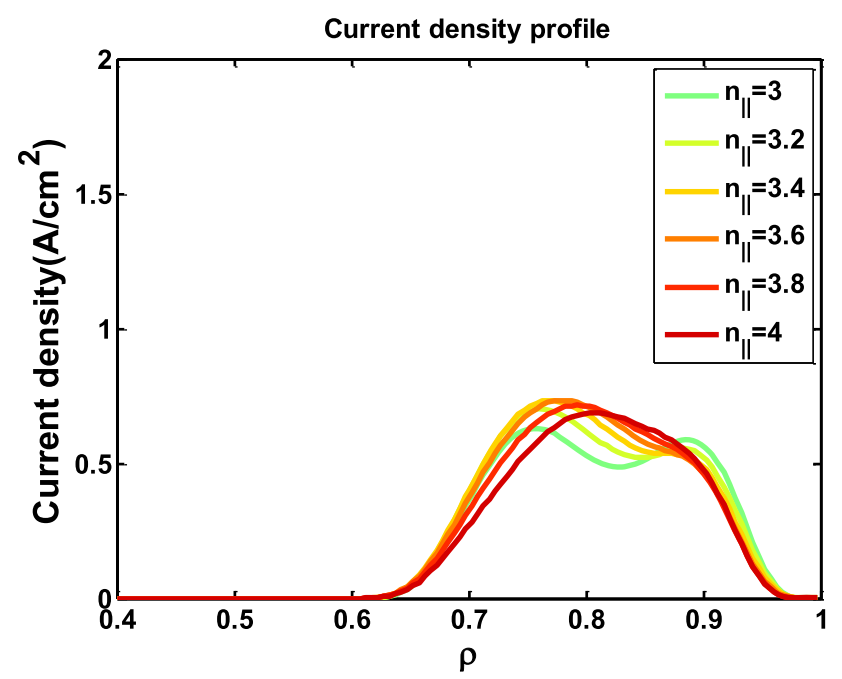

Fig. 3 Radial profile of driving current density at different $n_{\|}$for $B_{\mathrm{T}}=6 \mathrm{~T}, I_{\mathrm{p}}=7.6 \mathrm{MA}, n_{\mathrm{e}}=7.84 \times 10^{19} \mathrm{~m}^{-3}, T_{\mathrm{e}}=25.37 \mathrm{keV}$, wave frequency $f=1.5 \mathrm{GHz}$ (Rays emit from the middle plane of the low field side)

varied over the range 3 to 4 in steps of 0.2 . The shape of absorption profile is the same as of the current drive. The independence of the current drive and magnitude on $n_{\|}$is a result of the nature of the wave propagation and strong single-pass damping of these high harmonic fast waves [17].

\section{Poloidal Emission Position}

Figure 4 shows the radial profiles of driving current density with the rays launched from different poloidal angles. Within the range of $0^{\circ}-85^{\circ}$, the width of driving current density profile and the peak value first increase and then decrease, and the radial position corresponding to the peak value first moves inward and then outward. When the poloidal angle is $45^{\circ}$, the peak value of driving current profile is the largest, the profile is the widest (about 0.3), and the peak position is at $\rho=0.72$. Similarly, within the range of $270^{\circ}-355^{\circ}$, when the poloidal angle is $290^{\circ}$, the peak value of driving current profile is the largest, the profile is the widest (about 0.25 ), and the peak position is at $\rho=0.78$.

Figure 5 show the results of the high field side. When the poloidal angle is $180^{\circ}$, the peak value of driving current profile is the largest, the profile is the widest (about 0.2), and the peak position is at $\rho=0.6$.

\section{The influence of Plasma Parameters}

Figure 6 shows the peak value and the position of the driven current density profile with different temperatures and densities. The abscissa and ordinate coordinates in the figure are multiples of the plasma center electron temperature $T_{\mathrm{e}}=25.37 \mathrm{keV}$ and plasma center electron density $n_{\mathrm{e}}=7.84 \times 10^{19} \mathrm{~m}^{-3}$ respectively. Considering the position of peak value and peak value on the normalized minor 

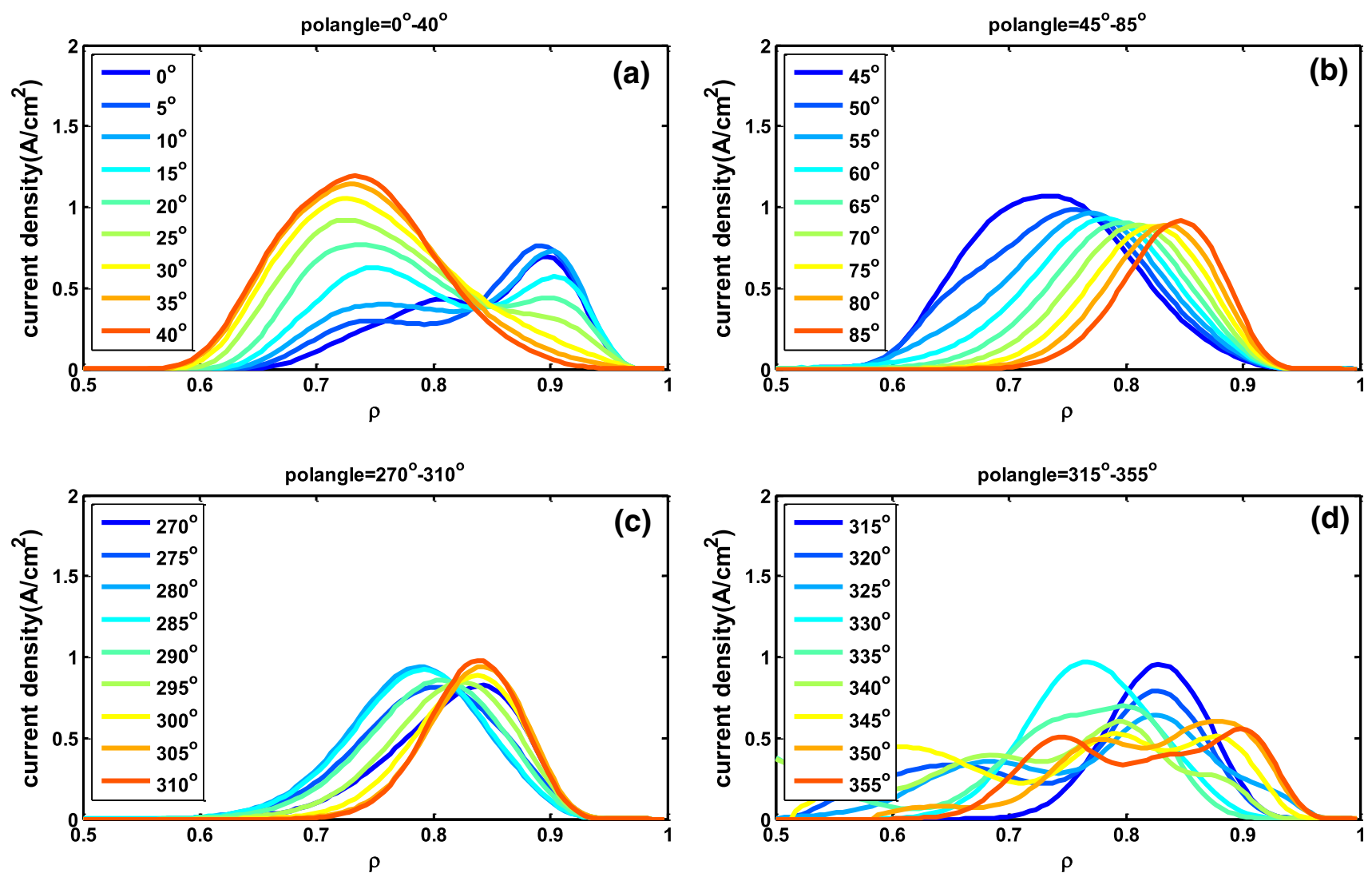

Fig. 4 Radial profile of driving current density at different poloidal angles for $B_{\mathrm{T}}=6 \mathrm{~T}, I_{\mathrm{p}}=7.6 \mathrm{MA}, n_{\mathrm{e}}=7.84 \times 10^{19} \mathrm{~m}^{-3}, T_{\mathrm{e}}$ $=25.37 \mathrm{keV}$, wave frequency $f=1.5 \mathrm{GHz}, n_{\|}=2.3$, poloidal angles were varied over the range $0^{\circ}$ to $85^{\circ}$ and $270^{\circ}$ to $355^{\circ}$ (also as $-90^{\circ}$

to $85^{\circ}$ ), interval of $5^{\circ}$. The poloidal angle is defined as the middle plane in the low field side is $0^{\circ}$ and the middle plane in the high field side is $180^{\circ}$, counterclockwise rotation of $360^{\circ}$ can contain the entire poloidal profile

radius, the result obtained with the combination of $\left(1 \times 25.37 \mathrm{keV}, 0.8 \times 7.84 \times 10^{19} \mathrm{~m}^{-3}\right)$ is better than the initial value of unity multipliers.

\section{Travelling Wave Antenna}

Use of a travelling wave antenna (TWA) provides a very narrow $n_{\|}$spectrum [17], which consists of a series of circular passive current straps, the first and last two are connected to the input port and the output port respectively, the input port is connected to the power source, and the output port is connected to the dummy load [23]. The specific working mechanism can be found in [24, 25].

Analyzing the influence of antenna size on its performance using the commercial software package-CST, the optimal structure size of antenna model is obtained as follows: The antenna is $130 \mathrm{~mm}$ in poloidal direction, $450 \mathrm{~mm}$ in toroidal direction and $200 \mathrm{~mm}$ in radial depth. Where, the length of the current strap is $80 \mathrm{~mm}$, the width of the current strap is $10 \mathrm{~mm}$, and the distance between the center of two adjacent current straps is $20 \mathrm{~mm}$. There are

16 current strap arrays (shown in Fig. 7). The antenna array has four feed ports (as \#1, \#2, \#3 and \#4 shown in Fig. 1), which connect to the beginning current strap and the end current strap separately, where RF wave power is fed in from \#1 and \#2, \#3 and \#4 connect to the load to absorb the remaining power.

The results of frequency sweep calculation are shown in Fig. 8, which includes the reflection coefficient S11 of \#1 and the transmission coefficient S41 from \#1 to \#4. At frequency $f=1389 \mathrm{MHz}, \mathrm{S} 11$ is minimal as $-46 \mathrm{~dB}$, which indicates the little reflection of $\# 1$, and in a wider range (about $60 \mathrm{MHz}$ ), S11 is below $-20 \mathrm{~dB}$. Besides, S41 is basically stable at $-5 \mathrm{~dB}$, which indicates that the mutual coupling between the current straps in this frequency domain is good. Very little power is left up to \#4, which means the power is effectively radiated to the plasma through mutual coupling between the current straps.

As for antenna size optimization, this paper only gives an example of the influence of antenna strap length on $\mathrm{S}$ parameter (shown in Figs. 9, 10). Change the current strap length y_strap from 75 to $85 \mathrm{~mm}$ interval of $5 \mathrm{~mm}$ for the 

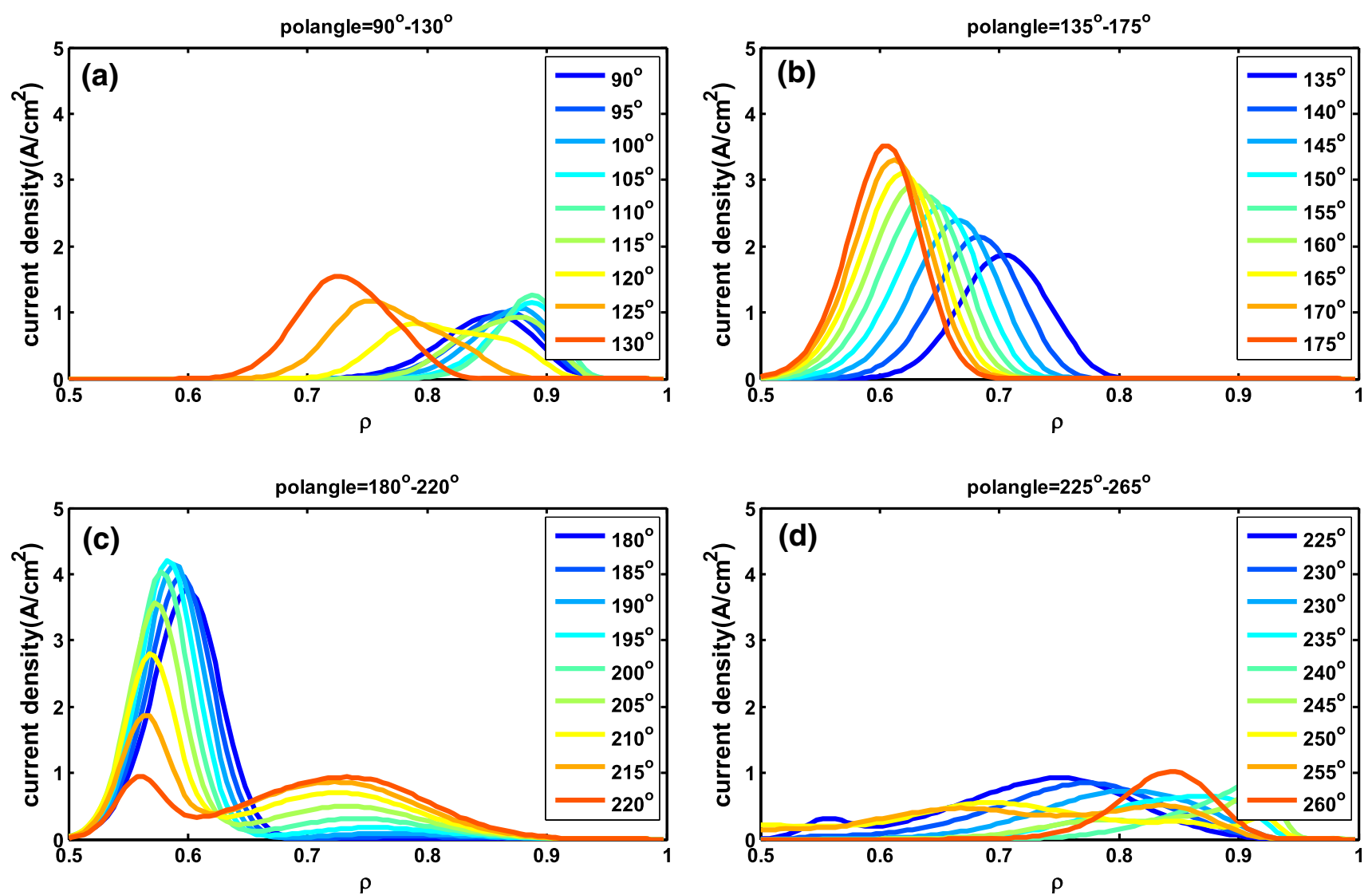

Fig. 5 Radial profile of driving current density at different poloidal angles for same parameters in case of Fig. 4 but poloidal angle was varied over the range $0^{\circ}$ to $85^{\circ}$ and $270^{\circ}$ to $355^{\circ}$ (also as $-90^{\circ}$ to $85^{\circ}$, low field side), $90^{\circ}-265^{\circ}$ (high field side) in steps of $5^{\circ}$ (high field side)
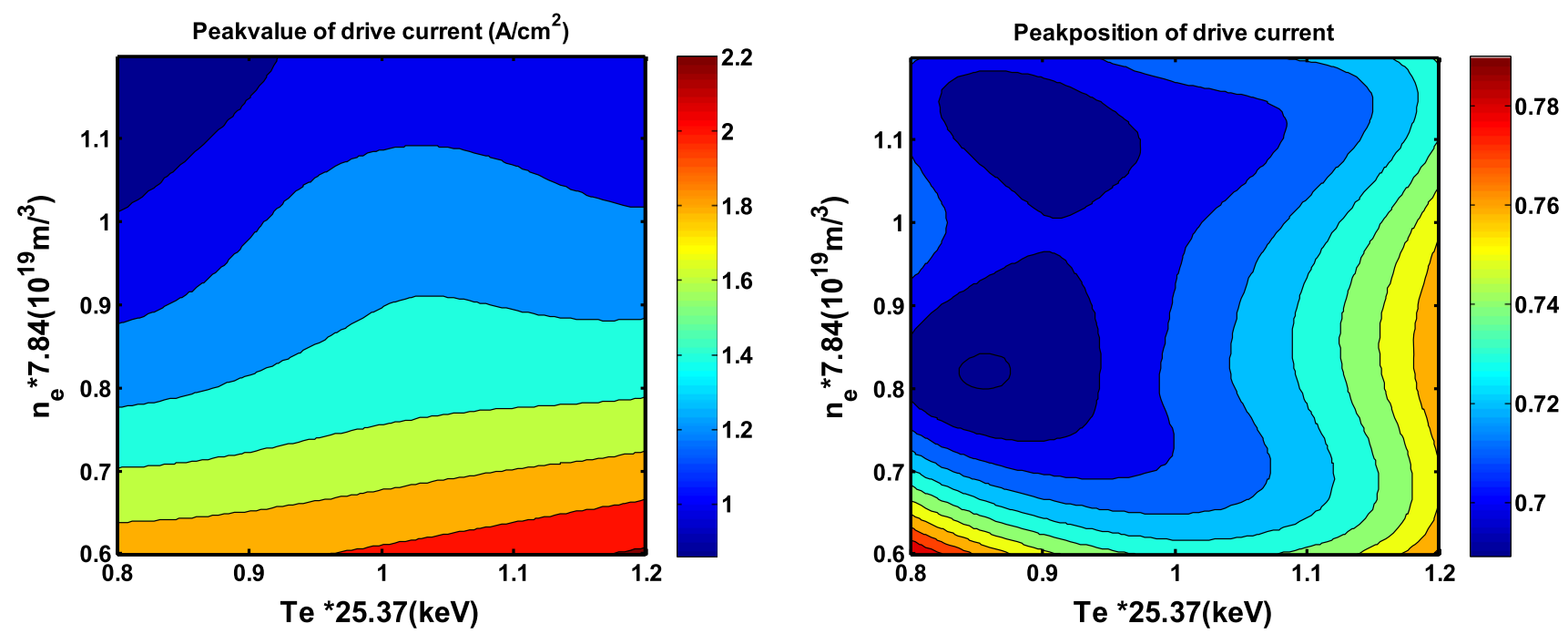

Fig. 6 The peak value and the position of the driven current density profile with different temperatures and densities for $B_{\mathrm{T}}=6 \mathrm{~T}, I_{\mathrm{p}}=7.6 \mathrm{MA}$, $T_{\mathrm{e}}=25.37 \mathrm{keV}, n_{\mathrm{e}}=7.84 \times 10^{19} \mathrm{~m}^{-3}$, wave frequency $f=1.5 \mathrm{GHz}, n_{\|}=2$, poloidal angles $45^{\circ}$

width of the current strap is $10 \mathrm{~mm}$, and the distance between the centers of two adjacent current straps is $20 \mathrm{~mm}$. At resonance frequency (1389 MHz), S11 is significantly smaller with y_strap $=80 \mathrm{~mm}$ than the other two and S41 is closer to zero in the wider frequency domain, which indicates the good mutual coupling of antennas.

Near the resonant frequency of the antenna, the Voltage Standing Wave Ratio (VSWR) reaches a minimum close to 
Fig. 7 Model of an sixteenstrap TWA section in its antenna box

Current strap

Fed port

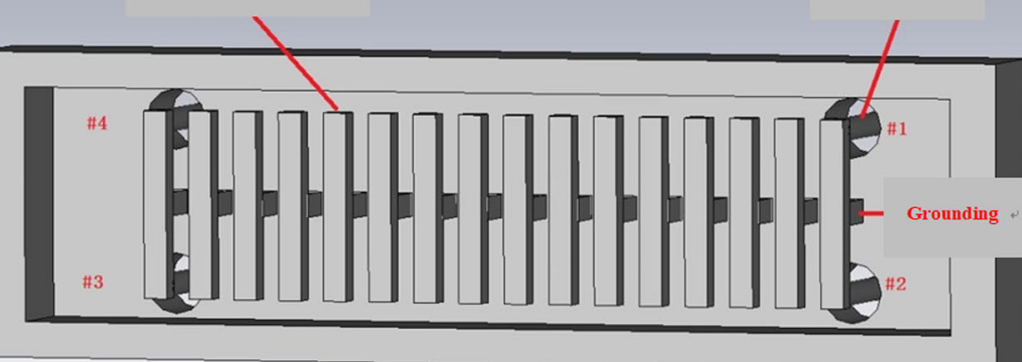

S-Parameters [Magnitude in dB]

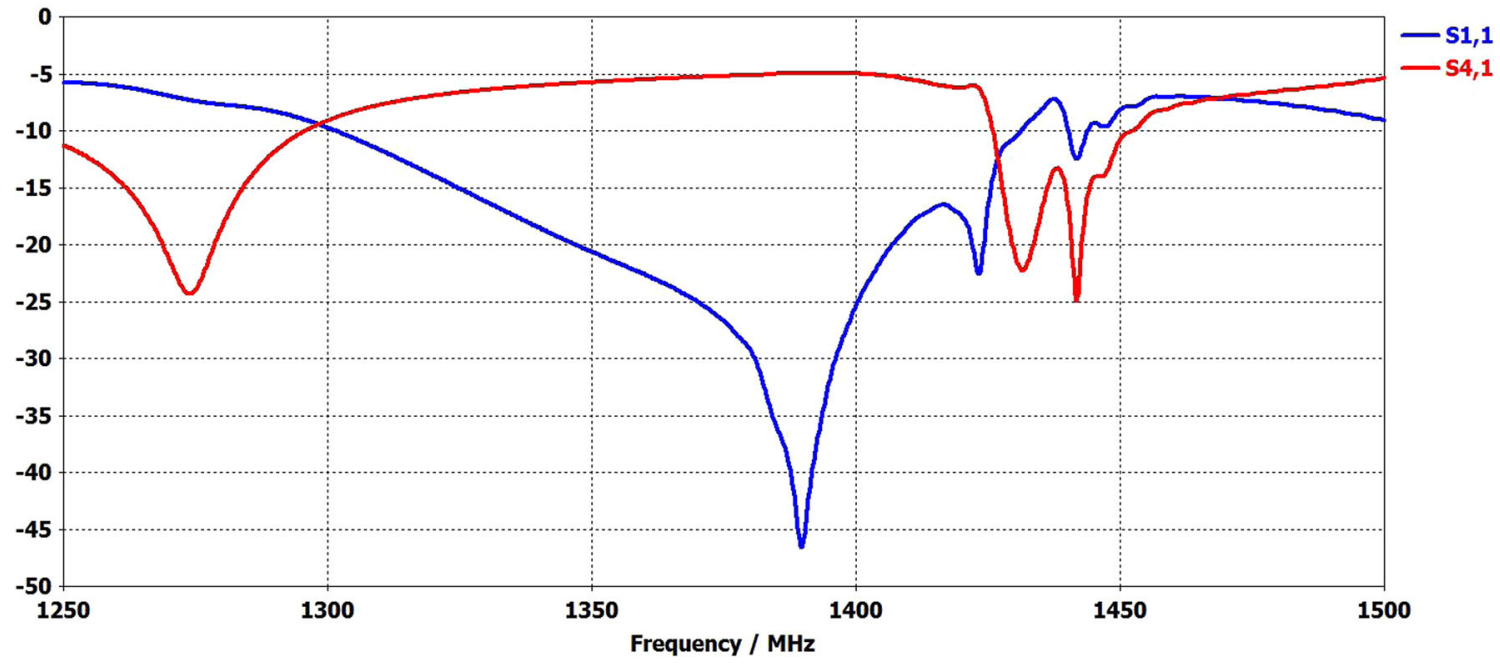

Fig. 8 Influence of frequency on antenna performance

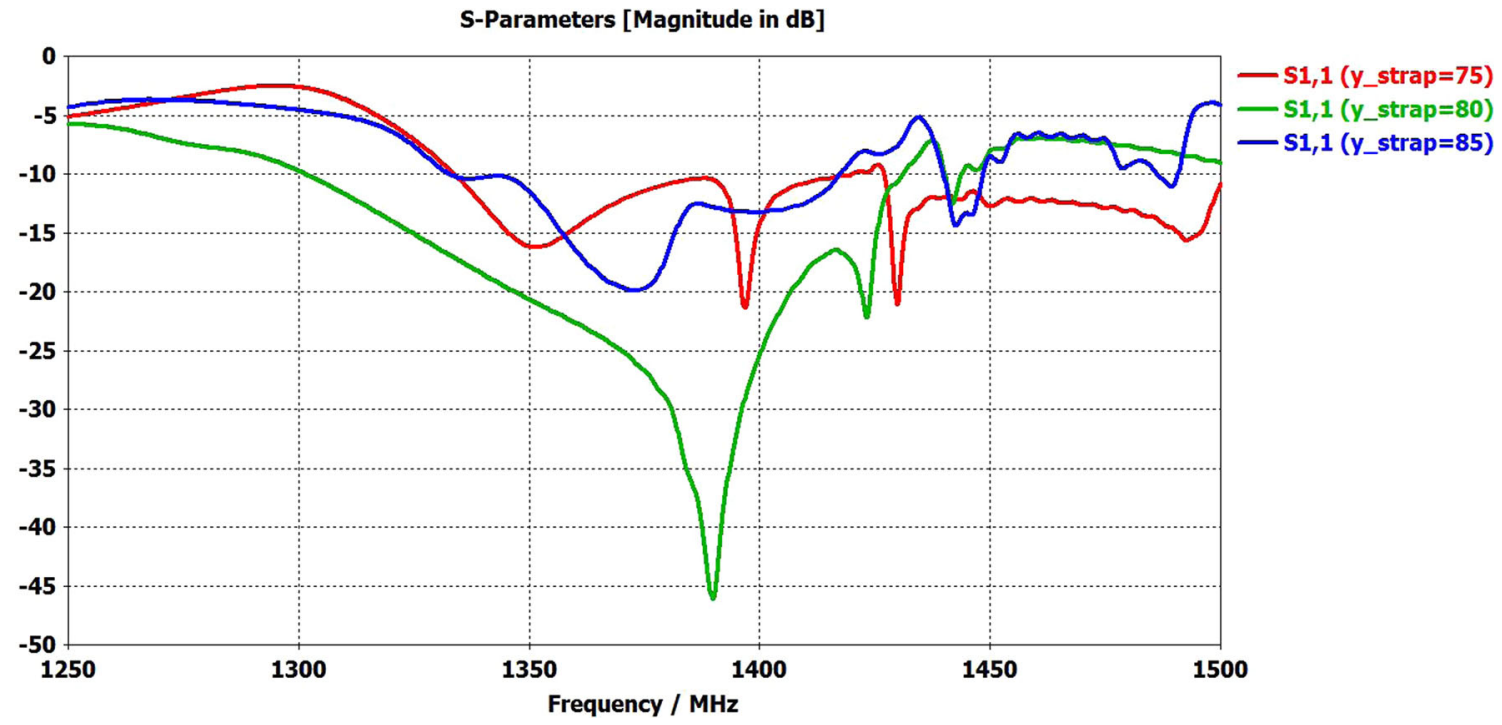

Fig. 9 Influence of the length of the current strap on S11 


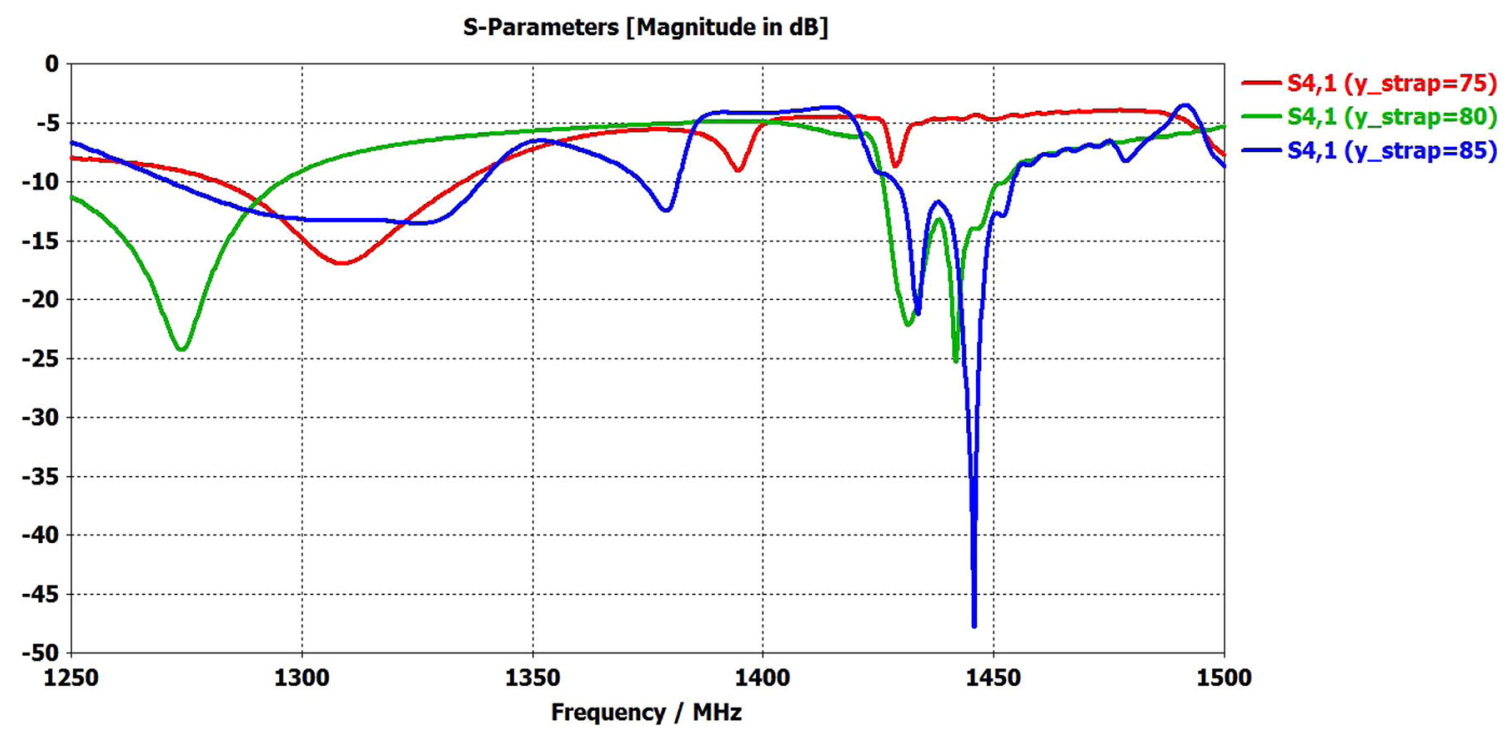

Fig. 10 Influence of the length of the current strap on S41

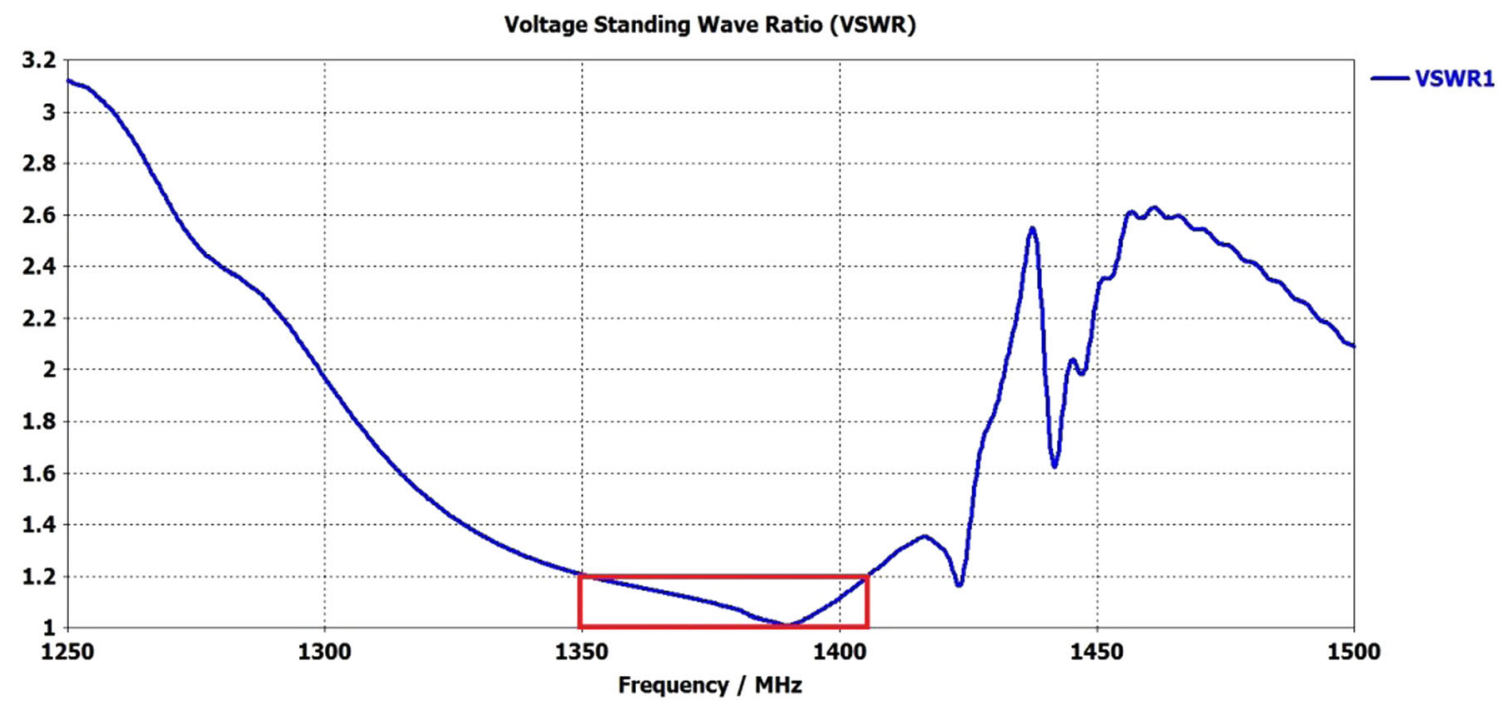

Fig. 11 Antenna \#1 feed voltage standing wave ratio

1 and VSWR $<1.2$ is obtained for the antenna in the bandwidth of $50 \mathrm{MHz}$ (Fig. 11). According to operating experience, it is completely possible to avoid external matching system in this frequency domain.

\section{Conclusions}

Introducing briefly of helicon wave theory and modelling with the GENRAY code show that helicon wave can drive off-axis current under CFETR design parameters under suitable plasma conditions: (1) high enough frequency which is greater than $1 \mathrm{GHz}$ that the wave acquired the whistler-like property of propagating nearly along a field line, giving the wave trajectories a spiral character; (2) considering the position of peak value and peak value on the normalized minor radius, the result obtained with the combination of the plasma center electron temperature $T_{\mathrm{e}}=1 \times 25.37 \mathrm{keV}$, and plasma center electron density $n_{\mathrm{e}}=0.8 \times 7.84 \times 10^{19} \mathrm{~m}^{-3}$ is a good option for CFETR; (3) the total driven current is not very sensitive to the launched $n_{\|}$, as shown by the scans. The travelling wave antenna is a good option for launching the wave with a very narrow $n_{\|}$spectrum. Using the commercial software package-CST, the electromagnetic characteristics of the TWA are analyzed and optimized VSWR was achieved. Relevant results provide theoretical basis for CFETR antenna engineering design. 
Acknowledgements This work was supported by: (1)National Natural Science Foundation of China under Grant Nos. 11905084; (2) National key Research and Development program (Grant Nos. 2016YFA0400600 and 2016YFA0400601); (3) Comprehensive Research Facility for Fusion Technology Program of China under Contract No. 2018-000052-73-01-001228.

Open Access This article is licensed under a Creative Commons Attribution 4.0 International License, which permits use, sharing, adaptation, distribution and reproduction in any medium or format, as long as you give appropriate credit to the original author(s) and the source, provide a link to the Creative Commons licence, and indicate if changes were made. The images or other third party material in this article are included in the article's Creative Commons licence, unless indicated otherwise in a credit line to the material. If material is not included in the article's Creative Commons licence and your intended use is not permitted by statutory regulation or exceeds the permitted use, you will need to obtain permission directly from the copyright holder. To view a copy of this licence, visit http://creativecommons. org/licenses/by/4.0/.

\section{References}

1. R. Koch et al. in Proceedings of the 19th Topical Conference (Newport, RI, 2011) (Melville, NY: AIP, 2011), p. 349

2. Y.T. Song, et al. in IEEE 25th symposium on fusion engineering (SOFE) (2013)

3. Y. Wan et al., Nucl. Fusion 57(10), 102009 (2017)

4. X.F. Liu et al., J. Fusion Energ. 34(6), 1438-1444 (2015)

5. J. Chen et al., Plasma Phys. Control. Fusion 59(7), 075005 (2017)

6. X. Jian et al., Nucl. Fusion 57(4), 046012 (2017)
7. N. Shi et al., Nucl. Fusion 57(12), 126046 (2017)

8. C. Gormezano et al., Chapter 6: steady state operation. Nucl. Fusion 47(6), S285-S336 (2007)

9. E. Lerche, et al. in AIP Conference. American Institute of Physics, pp. 338-341 (2014)

10. T. Franke, et al. in AIP Conference (American Institute of Physics, 2014), pp. 207-210

11. P. Franzen, U. Fantz, Fusion Eng. Des. 89(11), 2594-2605 (2014)

12. C. Gormezano et al., Plasma Phys. Control. Fusion 28, 1365 (1986)

13. S.C. Jardin et al., Fusion Eng. Des. 38, 27 (1997)

14. R. Prater et al., Nucl. Fusion 54(8), 083024 (2014)

15. M. Brambilla, Kinetic Theory of Plasma Waves: Homogeneous Plasmas (Oxford University Press, Oxford, 2008)

16. V.L. Vdovin, Plasma Phys. Rep. 39(2), 95-119 (2013)

17. R. Prater et al., Nuc. Fusion 54(8), 083024 (2014)

18. R.W. Harvey, A.P. Smirnov, The GENRAY Ray Tracing Code, CompX Report CompX-2000-01 (2001)

19. S.C. Chiu et al., Nucl. Fusion 29, 2175 (1989)

20. D.A. Ehst, C.C. Karney, Nucl. Fusion 31, 1933 (1991)

21. N. Shi et al., Fusion Eng. Des. 112, 47-52 (2016)

22. M. Kikuchi et al., Chapter 6: Fusion Physics (IAEA, Vienna, 2012)

23. C.P. Moeller et al. Radio frequency power in plasmas, in Proceedings of the 10th Topical Conference (Boston, MA) (Melville, NY: AIP, 1994), p. 323

24. R. Ragona, A. Messiaen, Nucl. Fusion 56(7), 076009 (2016)

25. S.J. Wang et al., Nucl. Fusion 57(4), 046010 (2017)

Publisher's Note Springer Nature remains neutral with regard to jurisdictional claims in published maps and institutional affiliations. 